\title{
Synoptic and dynamic characteristics of selected deep depressions over Cyprus
}

\author{
K. A. Nicolaides ${ }^{1}$, S. C. Michalelides ${ }^{1}$, and T. Karacostas ${ }^{2}$ \\ ${ }^{1}$ Meteorological Service, 28, Nikis Ave., Nicosia, CY-1028, Cyprus \\ ${ }^{2}$ Department of Meteorology and Climatology, Aristotelian University, Thessaloniki, Greece
}

Received: 31 October 2005 - Revised: 17 December 2005 - Accepted: 11 January 2006 - Published: 22 February 2006

\begin{abstract}
In this study, the spatial and temporal distributions of dynamic and synoptic characteristics of a selection of 32 deep baroclinic depressions have been investigated. The study covers the cold period months of November till March, in the period from 1 November 1986 to 31 March 2003. For the needs of the study, several synoptic characteristics of these depressions have been extracted. Also, several dynamic characteristics during the evolution of the depressions were studied: relative vorticity, divergence, vertical motion and a static stability parameter. The results are presented in the form of isobaric distributions over, three tropospheric isobaric levels, namely the lower $850 \mathrm{hPa}$, the middle $500 \mathrm{hPa}$ and the upper $300 \mathrm{hPa}$.
\end{abstract}

\section{Introduction}

The area of the Mediterranean is situated in the transition zone between the subtropical highs to the south and the mid latitude lows to the north, which are responsible for the prevailing westerly air flow. This suggests that the main reason for the climatic characteristics of the area and also for a lot of their changes is due to the circulation of the medium and upper troposphere (Reiter, 1975; Radinovic, 1987; Jacobeit, 1987).

Cyclonic activity has long been recognized, as a frequent meteorological situation over the area (Petterssen, 1956). A lot of effort has been made, not only towards the direction of quantifying the cyclonic activity, but also in identifying areas of the Mediterranean with a more frequent cyclogenetic capacity (Reiter, 1975; Radinovic, 1987).

Lately, with the development of identification methods based on mechanical recognition, greater emphasis has been given towards the direction of frequent cyclonic activity over the area (Triggo et al., 1999).

Correspondence to: K. Nicolaides

(kleanthi@spidernet.com.cy)
Flocas et al. (2001) concluded that the area of the Mediterranean has three sub areas with increased cyclogenetic potential: the Gulf of Genoa, the area of south Italy and the area of Cyprus. Flocas et al. (2001) noted that although the cyclogenetic potential of the above mentioned areas is high throughout the year, the depressions' characteristics are different from one area to another. Maheras et al. (2002) showed that cyclonic activity in each of the above mentioned areas can be found also with a seasonal variation of their characteristics. The general dynamic characteristics of the cyclonic activity over the area of the Mediterranean, has been examined also by other researchers (Michaelides, 1987; Prezerakos and Michaelides, 1989; Michaelides et al., 1999; Nicolaides et al., 2004).

Climatologically, the area of the Mediterranean is characterized by a long warm and dry period lasting from 5 to 7 months (Blanchet, 1976; Maheras, 1985) and a short relatively wet and cold period, lasting for the rest of the year. During the cold season, the weather over the area of the Eastern Mediterranean is mainly dependent on baroclinic depressions which either reach the area from the surrounding region or form over the area (El-Fandy, 1946; Kallos and Metaxas, 1980). These winter depressions are relatively frequent, almost one every week, (Michaelides et al., 2004; Nicolaides, 2005) and have a more intense baroclinic character compared to the depressions from other Mediterranean areas (Maheras et al., 2002).

The aim of the present study is the investigation of the synoptic and dynamic characteristics during the evolution of deep depressions which affect the area of Cyprus. Such information can be considered as diagnostic, but it can assist local weather forecasters in understanding the behavior of these synoptic systems and the impact they can have on local weather. 
Table 1. Number of deep depressions in the month in which they have first made their appearance in the area.

\begin{tabular}{ccccccc}
\hline Month & November & December & January & February & March & Total \\
\hline Number of depressions & 3 & 8 & 6 & 6 & 9 & 32 \\
\hline
\end{tabular}

Table 2. Number of depressions tabulated with respect to the value of their innermost closed isobar.

\begin{tabular}{cccccc}
\hline M.S.L Pressure $(\mathrm{hPa})$ & 988 & 992 & 996 & 1000 & Total \\
\hline Number of depressions & 1 & 2 & 6 & 23 & 32 \\
\hline
\end{tabular}

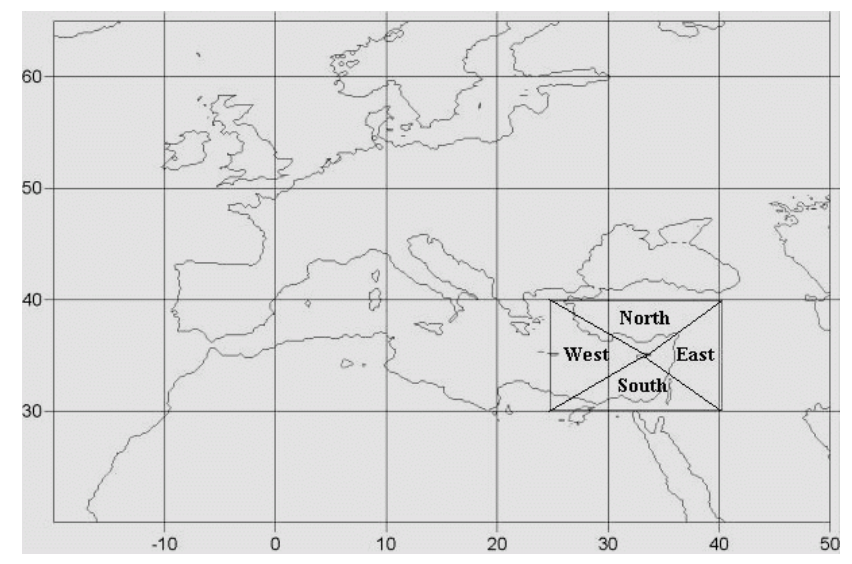

Fig. 1. The study area used for the mathematical calculations; the west direction with regard to Cyprus referred to in the text is shown.

\section{Data and methodology}

The present study focuses on the deep depressions which have affected the area of Cyprus during the cold months (November till March), in the period from the 1 November 1986 to 31 March 2003. The area of study is bounded by the meridians $25^{\circ} \mathrm{E}$ and $40^{\circ} \mathrm{E}$ and the parallel circles $30^{\circ} \mathrm{N}$ and $40^{\circ} \mathrm{N}$ (see Fig. 1).

For the identification of depressions, Mean Sea Level (MSL) synoptic charts for 12:00 UTC archived by the Cyprus Meteorological Service and analyzed every $4 \mathrm{hPa}$ were used. In order to select the depressions the following criterion was adopted: "on the corresponding MSL analysis, the cyclonic system must have at least one closed isobar within the area of study with pressure equal to, or less than $1000 \mathrm{hPa}$ and the depression must be entering the area from the west". For every deep depression selected, an inventory of its synoptic characteristics and evolution was maintained.

The inventory of each depression was used to determine the time of its maximum deepening (time D0). The times corresponding to 24 and $48 \mathrm{~h}$ before and 24 and $48 \mathrm{~h}$ after D0 were termed as D-1, D-2 and D+1 and D+2, respectively.
For each of the above times, namely D-2, D-1, D0, D+1 and $D+2$, the relative vorticity $(\zeta)$, the divergence of the horizontal wind vector $(\delta)$, the vertical motion $(\omega)$ and a parameter of static instability $(\sigma)$, at the standard isobaric levels of 850,500 and $300 \mathrm{hPa}$, were calculated. These fields were subsequently used to calculate the average distributions corresponding to the deep depressions that affected the area of Cyprus and originated from the west direction. The numerical form of the equations used for the calculations are:

$$
\begin{aligned}
& \delta=\frac{1}{r \cos \phi} \frac{\Delta u}{\Delta \lambda}+\frac{1}{r} \frac{\Delta v}{\Delta \phi}-v \frac{\tan \phi}{r} \\
& \zeta=\frac{1}{r \cos \phi} \frac{\Delta v}{\Delta \lambda}-\frac{1}{r} \frac{\Delta u}{\Delta \phi}+u \frac{\tan \phi}{r} \\
& \frac{\Delta \omega}{\Delta p}=-\delta, \sigma=\frac{g T}{c p}-\frac{p g}{R} \frac{\Delta T}{\Delta p}
\end{aligned}
$$

where $r$, refers to the radius of earth, $\lambda$ longitude, $\phi$ the latitude, $u$ and $v$ the zonal and meridional component of the horizontal wind vector, respectively, $g$ the vertical component of the vector of the acceleration of gravity, $T$ the temperature, $c_{p}$ the specific heat of dry air under constant pressure, $p$ the atmospheric pressure and $R$ the universal gas constant. The parameter $\sigma$, was used in energetic studies (e.g. Michaelides, 1987). In this paper, the results on divergence and vertical motions are not presented for brevity. For the same reason, the discussion here is limited to the depressions which affected Cyprus originating from the west direction (see Fig. 1).

The data used for the mathematical calculations are the NCEP/NCAR global analyses for 00:00 UTC, with a grid of $2.5^{\circ} \times 2.5^{\circ}$, archived by the National Centres for Environmental Prediction of USA. The area of the calculations is bounded by the meridians $20^{\circ} \mathrm{W}$ and $50^{\circ} \mathrm{E}$ and the parallel circles $20^{\circ} \mathrm{N}$ and $65^{\circ} \mathrm{N}$. This area is larger than the area used for the identification of depressions, thus providing a more general view of the dynamical processes associated with these depressions (Fig. 1).

\section{Results}

For the needs of the study, several synoptic characteristics of the depressions which are considered have been considered (here only the. mean and the mode values of their innermost closed isobar are presented);

A total of 32 deep depressions have been considered, entering the area of study from the west and fulfilling the above mentioned criterion. The vast majority of these depressions 
(29) affected the area of Cyprus during the period from December to March and only a few of them, namely, 3 during November (see Table 1).

It was also found that the depressions with atmospheric pressure of their innermost closed isobar equal to $1000 \mathrm{hPa}$ are more frequent, while the deepest that had a pressure of $988 \mathrm{hPa}$, have affected the area of Cyprus during February 1986 (see Table 2).

The (average) dynamical characteristics of these deep depressions were also studied, in an attempt to obtain a global idea of the underlying dynamic mechanisms and physical processes involved in the evolution of deep baroclinic systems. In the following, a discussion is made of the most outstanding features of the average spatial distribution of various dynamical parameters during the evolution of these depressions, from time $\mathrm{D}-2$ to $\mathrm{D}+2$. However, only the respective distributions for D-2 (Fig. 2), D0 (Fig. 3) and D+2 (Fig. 4) are displayed here.

\subsection{Time D-2}

On the $850 \mathrm{hPa}$ surface, high static stability index values (greater than $1.5 \mathrm{~K}^{2} \mathrm{~s}^{-1}$ ) are found over the continental Europe, implying an increased stability of the lower tropospheric continental air (Fig. 2). The highest static stability values are observed over northeast Europe and Russia, indicating the increased stability of the lower tropospheric continental air due to the extension of the Siberian high. In contrast, the lower values (less than $1.0 \mathrm{~K}^{2} \mathrm{~s}^{-1}$ ) are found over maritime areas, indicating the increased instability of the lower maritime tropospheric air. The lowest values of static stability index (values less than $0.9 \mathrm{~K}^{2} \mathrm{~s}^{-1}$ ) are observed over the central Mediterranean.

On the $500 \mathrm{hPa}$ surface, a weak trough is found at time D-2 over the area of central Europe; west Europe is under anticyclonic conditions and the area of central Europe is under cyclonic conditions. The trough axis extends from east Europe towards Tunis. The temperature field at the isobaric surface of $500 \mathrm{hPa}$ reveals warm advection over west and north Europe and cold advection over the trough area. Typical values for the geodynamic height and temperature over the area of Cyprus at time D-2 is $5600 \mathrm{~m}$ and $252 \mathrm{~K}$, respectively.

The geodynamic height field at the isobaric level of $300 \mathrm{hPa}$ is similar to that of $500 \mathrm{hPa}$, suggesting anticyclonic conditions over west Europe and cyclonic conditions over central Europe. The relative vorticity field at $300 \mathrm{hPa}$ shows positive relative vorticity values over central and east Europe (strongest values over the Balkans and Italy) and negative relative vorticity values over west Europe (weakest values over the east Atlantic and UK). Advection of positive relative vorticity over the central Mediterranean is noted, resulting in a sharpening of the upper trough in the next hours and onset of cyclogenesis over the area west of Cyprus.
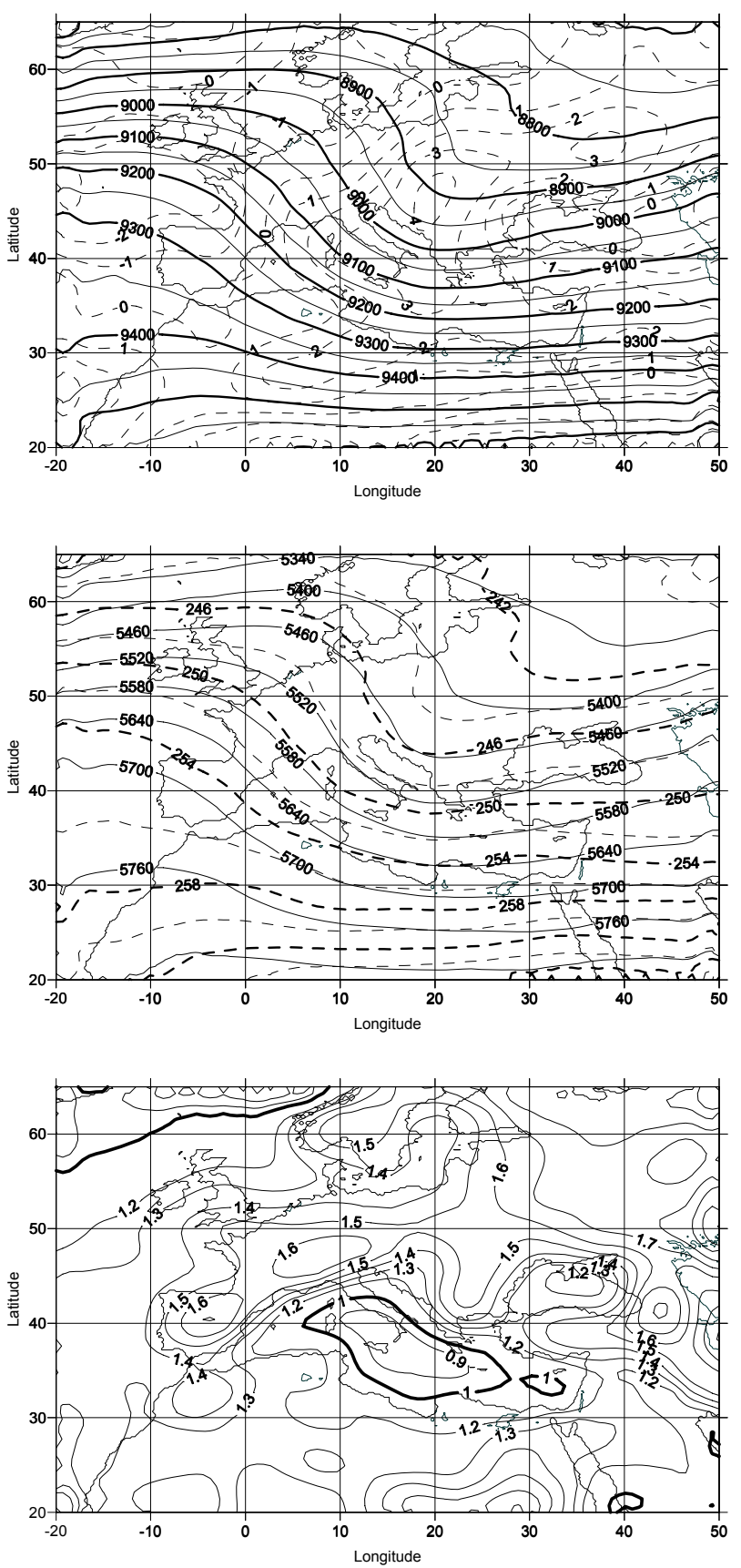

Fig. 2. Time D-2: Bottom: Static stability index at $850 \mathrm{hPa}$ contours (solid lines, $\mathrm{K}^{2} \mathrm{~s}^{-1}$ ); Middle: $500 \mathrm{hPa}$ contours (solid lines, $\mathrm{m}$ ) and temperature (dashed lines, K); Top: $300 \mathrm{hPa}$ contours (solid lines, $\mathrm{m})$ and relative vorticity (dashed lines, $10^{-5} \mathrm{~s}^{-1}$ ).

\subsection{Time D-1}

At time D-1, static stability values on the $850 \mathrm{hPa}$ over the Mediterranean tend to decrease (values less than $0.8 \mathrm{~K}^{2} \mathrm{~s}^{-1}$ are found over the central Mediterranean). The decrease of static stability over Central Mediterranean implies that lower tropospheric maritime air becomes more unstable, resulting in enhanced lower tropospheric cloud formation. 

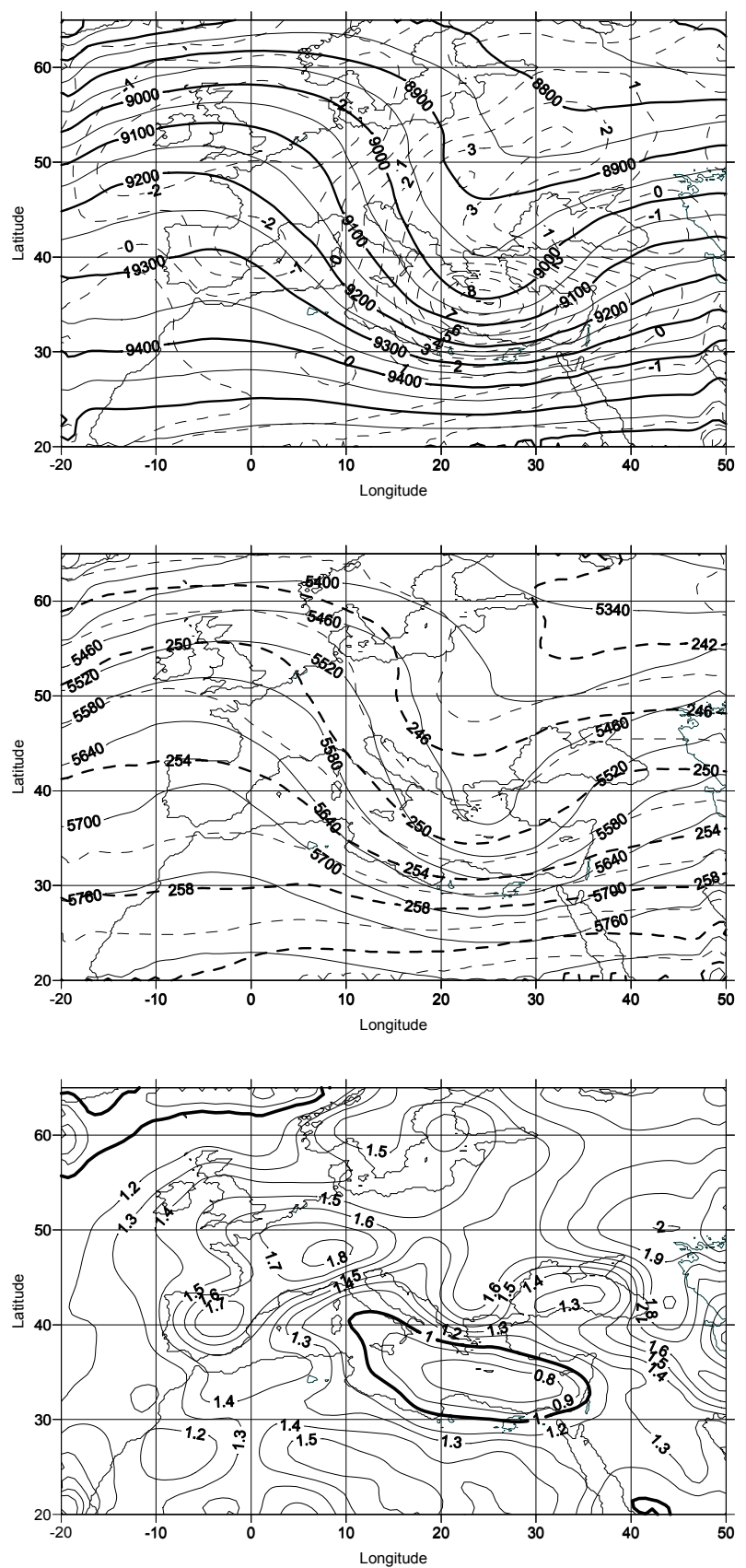

Fig. 3. Same as Fig. 2 but for D0.

At the $500 \mathrm{hPa}$ level, the trough is sharpening, resulting in lowering of geodynamic height and MSL pressure deepening over the area of the Balkans. Typical geodynamic height for the area of Cyprus is $5580 \mathrm{~m}$ (i.e. $20 \mathrm{~m}$ less than at time D2 ), The temperature field exhibits warm advection over west Europe (an area under anticyclonic conditions) and cold advection over the area of the Balkans (an area of cyclonic activity).

The geodynamic height at the isobaric surface of $300 \mathrm{hPa}$ shows the intensified anticyclonic and cyclonic conditions over west Europe and the Balkans, respectively. The field
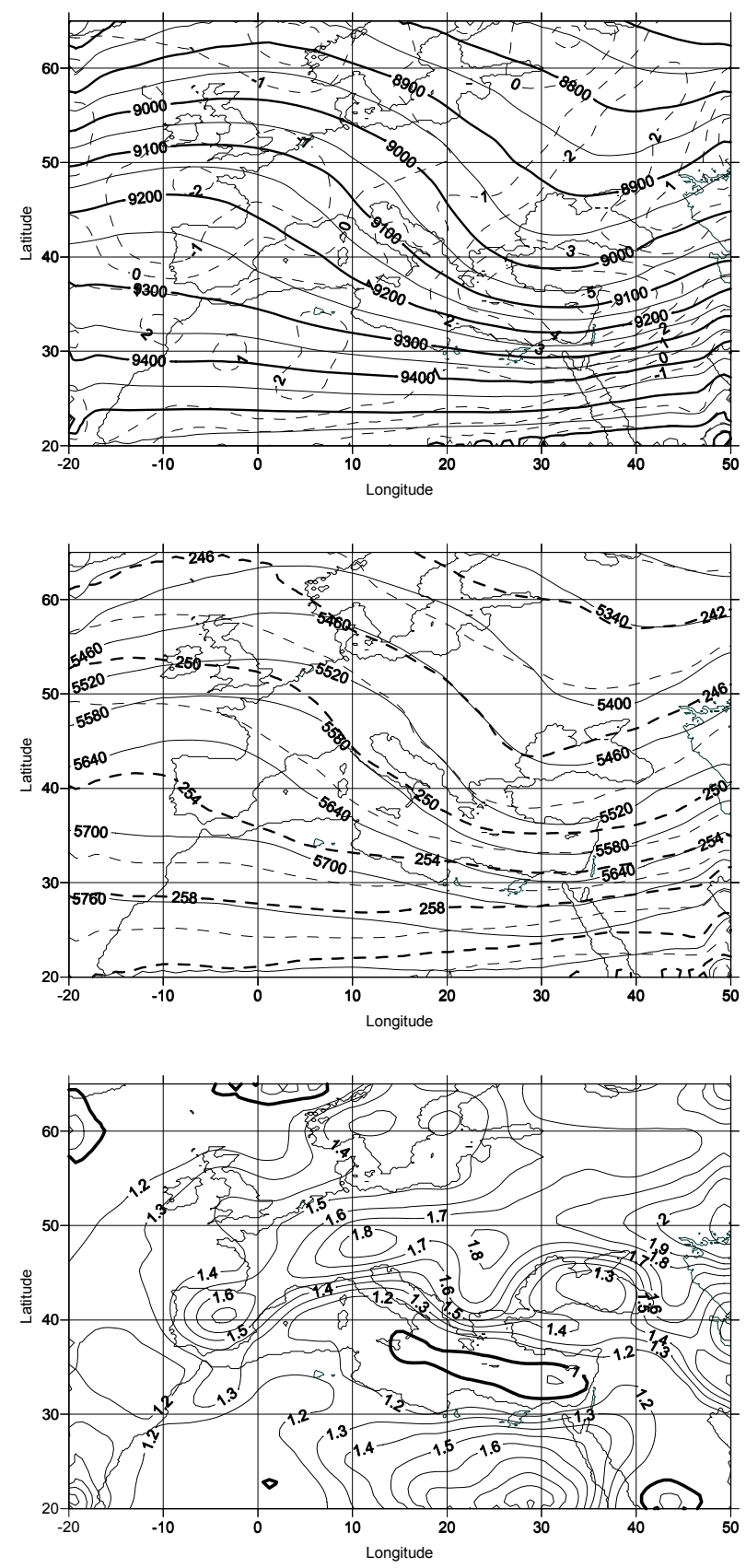

Fig. 4. Same as Fig. 2 but for D+2.

of relative vorticity is intensified (to more than $5 \times 10^{-5} \mathrm{~s}^{-1}$ over south Greece and less than $-4 \times 10^{-5} \mathrm{~s}^{-1}$ south of the British Isles). The continued advection of positive relative vorticity over Crete enhances the cyclone formed.

\subsection{Time D0}

A decrease of the $850 \mathrm{hPa}$ static stability values is observed at time D0: the lowest values (less than $0.8 \mathrm{~K}^{2} \mathrm{~s}^{-1}$ ) are observed over the area of Eastern Mediterranean (see Fig. 3) indicating that the lower tropospheric maritime air becomes increasingly unstable, through sensible heat transfer from the 
underlying warm Mediterranean waters and the low level release of latent heat (see Shay-El and Alpert, 1991).

At the isobaric level of $500 \mathrm{hPa}$ the baroclinic character of the depression is intensified, with cold air advection being observed over the Balkans and warm air advection east of $30^{\circ} \mathrm{E}$. The trough extends southwards, resulting in enhanced anticyclonic conditions over west Europe and enhanced cyclonic conditions over the Balkans the Aegean and further south. A typical value for geodynamic height over the area of Cyprus is $5540 \mathrm{~m}$ (i.e. $40 \mathrm{~m}$ less than at D- 1 and $60 \mathrm{~m}$ less than at D-2).

The intensified cyclonic activity can be also observed over the $300 \mathrm{hPa}$ isobaric surface with a deepening of the upper trough at this level and a simultaneous increase in relative vorticity (values greater than $8 \times 10^{-5} \mathrm{~s}^{-1}$ can be found over Crete - a typical value for relative vorticity at time D- 0 over the area of Cyprus is $4 \times 10^{-5} \mathrm{~s}^{-1}$ ).

\subsection{Time D+1}

At time D+1, low level static stability index values remain low over the area of the Eastern Mediterranean (values less than $0.8 \mathrm{~K}^{2} \mathrm{~s}^{-1}$ are found just south of Cyprus), favoring the lower tropospheric cloud formation.

The trough axis over the $500 \mathrm{hPa}$ isobaric surface is over west Minor Asia and a typical geodynamic height value for the area of Cyprus is $5520 \mathrm{~m}(20 \mathrm{~m}$ less than time D0, $60 \mathrm{~m}$ less than at time D- 1 and $80 \mathrm{~m}$ less than at time D-2). A typical temperature for the area of Cyprus is $250 \mathrm{~K}$, at this level. The area of west Europe remains under the influence of an upper ridge.

Over the upper tropospheric isobaric level of $300 \mathrm{hPa}$, the relative vorticity field maintains its positive values but, showing signs of weakening, since the maximum positive relative vorticity over Crete has values of less than $7 \times 10^{-5} \mathrm{~s}^{-1}$.

\subsection{Time D+2}

Finally, at time D+2 (Fig. 4), the lower tropospheric maritime air increases its stability, since the static stability values on the $850 \mathrm{hPa}$ level (values less than $1.0 \mathrm{~K}^{2} \mathrm{~s}^{-1}$ ) are generally increasing over the Mediterranean, indicating a decline of lower tropospheric cloud formation.

The trough over the $500 \mathrm{hPa}$ isobaric surface weakens, with an increase of the geodynamic heights. A typical geodynamic height over the area of Cyprus at time D+2 is $5530 \mathrm{~m}$ and a typical temperature for the same area is $250 \mathrm{~K}$. The ridge over west Europe weakens further more and the flow loses its marked meridional character.

A weakening trough is also observed over the upper tropospheric isobaric layer of $300 \mathrm{hPa}$. The ridge over west Europe weakens and the trough amplifies. Relative vorticity values continue to be positive over the area of the Mediterranean with their maximum over Eastern Mediterranean (more than $\left.5 \times 10^{-5} \mathrm{~s}^{-1}\right)$.

\section{Concluding remarks}

Some of the synoptic characteristics of depressions affecting the area of Cyprus during the cold months have been studied in this investigation. Generally, deep depressions are not frequent over the area of Cyprus. Most frequently, the value of the innermost isobar is $1000 \mathrm{hPa}$; ; very deep depressions (innermost closed isobar pressure less than $992 \mathrm{hPa}$ ) are very rare.

In association with the depressions studied, a strong dependence of the static stability index and geographical factors (i.e. maritime and continental regions) was noted. It seems that, during the cold season, the Mediterranean warmer sea waters but also the low level release of latent heat largely control the stability characteristics of the atmosphere.

The upper level isobaric circulation is characterized by a trough of longer wavelength during the period immediately before the maximum deepening of the MSL cyclone (i.e. at times D-2 and D-1); the wavelength shortens and the amplitude increases with maximum deepening (i.e. at time D0). The most intense baroclinic character of the depressions is found at times D0 and D+1.

The advection of positive relative vorticity seems to be crucial in the stages preceding the time of maximum cyclone deepening. The noticeable advection of relative vorticity just to the west of Cyprus during these stages leads to formation or further deepening and subsequent transfer into the study area.

Edited by: V. Kotroni and K. Lagouvardos

Reviewed by: anonymous referee

\section{References}

Blanchet, G.: Le temps au Liban. Approche d' une Climatologie Synoptique, Thèse 3ème Cycle, Lyon, T.I., 447p. (text et tab.) T.II (Atlas), 1976.

El-Fandy, M. G.: Barometric Lows of Cyprus, Q. J. Roy Met. Soc., 72, 291-306, 1946.

Flocas, H. A., Maheras, P., Karacostas, T. S., Patrikas, I., and Anagnostopoulou, C.: A 40-year Climatological study of relative vorticity distribution over the Mediterranean, Int. J. Climatol., 21, 1759-1778, 2001.

Jacobeit, J.: Variations of trough position and precipitation patterns in the Mediterranean Area, J. Climatol., 7, 453-476, 1987.

Kallos, G. and Metaxas, D. A.: Synoptic processes for the formation of Cyprus lows, Rivista Meteorologia Aeronautica, XL(23), 121-138, 1980.

Maheras, P., Flocas, H. A., Anagnostopoulou, C., and Patrikas, I.: On the vertical structure of composite surface cyclones in the Mediterranean region, Theoretical. and Applied Climatology, 71, 199-217, 2002.

Maheras, P.: A factorial analysis of Mediterranean precipitation, Arch. Met. Geoph. Biocl., Ser. B, 36, 1-14, 1985.

Michaelides, S. C.: Limited area energetics of Genoa cyclogenesis, Mon. Wea. Rev., 115, 13-26, 1987.

Michaelides, S., Evripidou, P., and Kallos, G.: Monitoring and predicting Saharan Desert Dust events in the Eastern Mediterranean, Weather, 54, 359-365, 1999. 
Michaelides, S., Nicolaides, K., and Karacostas, T.: Statistical characteristics of the cold season depressions over the area of Cyprus, Meteorologický Éasopis, 7, 61-66, 2004.

Nicolaides, K.: Synoptic and dynamic study of the depression cases affected the wider area of Cyprus during cold months, $\mathrm{PhD}$ thesis. Aristotelian University, Thessaloniki, Greece (in Greek), 2005.

Nicolaides, K., Michaelides, S., and Karacostas, T.: Spatial distribution of some dynamic parameters during the evolution of selected depressions over the area of Cyprus., Int.J. Climatol., 24, 1829-1844, 2004.

Petterssen, S.: Weather analysis and forecasting, McGraw-Hill, 1956.
Prezerakos, N. G. and Michaelides, S. C.: A composite diagnosis in sigma coordinates of the atmospheric energy balance during intense cyclone activity, Q. J. Roy Met. Soc., 115, 463-486, 1989.

Radinovic, D.: Mediterranean cyclones and their influence on the weather and climate, program on short and medium range weather prediction research (PSMP), W.M.O. Sofia, 1987.

Reiter, E. R.: Handbook for forecasters in the Mediterranean, Naval Postgraduate School, Monterey California, USA, 1975.

Shay-El, Y. and Alpert, P.: A diagnostic study of winter diabatic heating in the Mediterranean in relation to cyclones, Q. J. Roy Met. Soc., 117, 715-747, 1991.

Trigo, I. F., Davies, T. D., and Bigg, G. R.: Objective climatology of cyclones in the Mediterranean region, J. Climate, 12, 16851696, 1999. 